\title{
Non-Catalytic Benefits of Ni(II) Binding to an Si(111)-PNP Construct for PEC HER: Metal Ion Induced Flat Band Potential Modulation
}

\author{
Joseph M. Gurrentz and Michael J. Rose* \\ Department of Chemistry, University of Texas at Austin; Austin, TX 78712, USA \\ *corresponding author: mrose@cm.utexas.edu
}

Table of Contents

Page

Organic Synthesis and Nickel Metalation $\quad$ S2

Wafer Preparation $\quad$ S8

Photoelectrode Characterization $\quad$ S9

$\begin{array}{ll}\text { Figure S1 S12 } & \text { S1 }\end{array}$

Figure S2 $\quad \mathrm{S} 13$

$\begin{array}{ll}\text { Figure S3 } & \text { S14 }\end{array}$

$\begin{array}{ll}\text { Figure S4 } & \text { S15 }\end{array}$

Figure S5 $\quad$ S16

Table S1 $\quad$ S17

$\begin{array}{ll}\text { Table S2 } & \text { S17 }\end{array}$

$\begin{array}{ll}\text { References } & \text { S18 }\end{array}$ 


\section{Organic Synthesis and Nickel Metalation}

\section{2,6-Diiodo-4-bromoaniline}

p-Bromoaniline (1 equiv., $4.000 \mathrm{~g}$ ), pulverized $\mathrm{I}_{2}(1.2$ equiv., $7.082 \mathrm{~g}$ ), $80 \mathrm{~mL}$ of deionized water, and hydrogen peroxide (30\%, 2.4 equiv., $5.72 \mathrm{~mL})$ were added to a round bottom flask, which was fitted with a septum and an outlet needle. The mixture was sonicated for 90 minutes at room temperature then poured into an aqueous solution of sodium thiosulfate. The organic layer was extracted with ethyl acetate, separated from the aqueous layer, then dried over sodium sulfate. The product was purified by adding hexane to the crude solution of ethyl acetate, thus precipitating a pure off-white solid that was isolated by vacuum filtration. Yield: $30 \% .{ }^{1} \mathrm{H}$ NMR $\left(\mathrm{CDCl}_{3}\right): \delta 7.73$ (s 2H), 4.64 (s 2H) ppm. GCMS (EI+) $\mathrm{m} / z:[\mathrm{M}+\mathrm{H}]^{+}$ calculated for $\mathrm{C}_{6} \mathrm{H}_{4} \mathrm{BrI}_{2} \mathrm{~N}(\mathrm{M}), 422.7616$, 424.7596; observed, 422.9, 424.9.

\section{1,3-Diiodo-5-bromobenzene}

Concentrated $\mathrm{H}_{2} \mathrm{SO}_{4}$ was slowly added to a round bottom flask maintained at $0{ }^{\circ} \mathrm{C}$ containing solid 2,6diiodo-4-bromoaniline (1 equiv., $1.607 \mathrm{~g}$ ) and a stir bar until the aniline was completely solvated. Crystalline sodium nitrite ( 2.2 equiv., $0.576 \mathrm{~g}$ ) was added over ten minutes to the stirring solution, then the mixture was allowed to stir cold for 2 hours. After this duration the mixture was added dropwise onto ice $(\sim 30 \mathrm{~mL})$ and precipitates were removed by vacuum filtration. The collected filtrate was then added dropwise to a boiling solution of $\mathrm{CuSO}_{4} \cdot 5 \mathrm{H}_{2} \mathrm{O}(0.10$ equiv., $0.096 \mathrm{~g})$ in ethanol $(\sim 200 \mathrm{~mL})$ and allowed to reflux for one hour. The solution was then cooled to $0{ }^{\circ} \mathrm{C}$ affording a precipitate that was collected by vacuum filtration. This fluffy off-white solid was identified as pure 1,3-diiodo-5-bromobenzene. Yield: 7080\%. ${ }^{1} \mathrm{H}$ NMR $\left(\mathrm{CDCl}_{3}\right): \delta 7.98(\mathrm{t} 1 \mathrm{H}), 7.82(\mathrm{~d} 2 \mathrm{H}) \mathrm{ppm}$. GCMS $(\mathrm{EI}+) \mathrm{m} / z:[\mathrm{M}+\mathrm{H}]^{+}$calculated for $\mathrm{C}_{6} \mathrm{H}_{3} \mathrm{BrI}_{2}$ (M), 407.751, 409.749; observed, 407.7, 409.7.

\section{p-Allylnitrobenzene}

A solution of 1-bromo-4-nitrobenzene (1 equiv., $4.371 \mathrm{~g})$ and tetrakis(triphenylphosphine) palladium(0) (0.025 equiv., $0.499 \mathrm{~g})$, in dry dioxane $(\sim 240 \mathrm{~mL})$ was prepared in a Schlenk flask under a nitrogen atmosphere. A solution of potassium carbonate (2 equiv., $5.970 \mathrm{~g}$ ) in degassed $\mathrm{H}_{2} \mathrm{O}(40 \mathrm{~mL}$ ) was added to 
the flask followed by allylboronic acid pinacol ester (1.1 equiv., $4.00 \mathrm{~g})$. The reaction mixture was brought to reflux and allowed to stir for two days. The reaction mixture was then cooled to room temperature and the product was extracted into ethyl acetate. The aqueous layer was removed, and the organic layer was dried over sodium sulfate. Volatiles were removed from the organic layer via rotary evaporation, and various salts and unreacted boronic acid were removed from the resulting oily substance by a silica column chromatography using an 8:1 hexane/ethyl acetate mobile phase affording an orange oil containing a mix of $p$-allylnitrobenzene, and unreacted 1-bromo-4-nitrobenzene. Pure product was isolated by dissolving the eluent in an excess of pentane, which was then brought to $-5^{\circ} \mathrm{C}$ in a freezer. The desired product, $p$ allylnitrobenzene, remained solubilized in the cold pentane and was isolated via decantation, leaving behind the unreacted 1-bromo-4-nitrobenzene precipitate. Yield: 60-70\%. ${ }^{1} \mathrm{H} \mathrm{NMR}\left(\mathrm{CDCl}_{3}\right): \delta 8.15(\mathrm{~d} 2 \mathrm{H}), 7.33$ (d 2H), $5.93(\mathrm{~m} \mathrm{1H}), 5.15(\mathrm{~d} \mathrm{1H}), 5.09(\mathrm{~s} 1 \mathrm{H}), 3.49(\mathrm{~d} 2 \mathrm{H}) \mathrm{ppm}$. GCMS (EI+) m/z: $[\mathrm{M}+\mathrm{H}]^{+}$calculated for $\mathrm{C}_{9} \mathrm{H}_{9} \mathrm{NO}_{2}(\mathrm{M})$, 163.063; observed, 163.0.

\section{1-Bromo-3,5-bis(p-nitrophenyl-n-propyl)benzene}

A Schlenk flask under nitrogen atmosphere containing a stir bar and borane-dimethyl sulfide complex (2 M, 4.0 equiv., $2.94 \mathrm{~mL}$ ) was fitted with an addition funnel and suspended in an ice bath. A solution of $p$ allylnitrobenzene (3.6 equiv., $0.870 \mathrm{~g})$ in dry dioxane $(\sim 10 \mathrm{~mL})$ was then added dropwise to the cold borane solution. The resulting solution was allowed to warm up to room temperature over two hours while stirring. After this duration the solution was cooled to $0{ }^{\circ} \mathrm{C}$ and quenched with degassed water very slowly until the solution ceased to bubble, affording a solution of (4-nitrophenethyl)boronic acid. Separately, a solution of tetrakis(triphenylphosphine) palladium $(0)(0.03$ equiv., $0.051 \mathrm{~g})$ in dioxane $(\sim 50 \mathrm{~mL})$ was prepared in a Schlenk flask under nitrogen, to which 1,3-diiodo-5-bromobenzene (1 equiv. $0.600 \mathrm{~g}$ ) and a solution of $\mathrm{NaOH}$ (4.0 equiv., $0.235 \mathrm{~g})$ in degassed water $(\sim 30 \mathrm{~mL})$ were added. Finally, the (4-nitrophenethyl)boronic acid solution was added to the separate Schlenk flask via cannula. The reaction mixture was heated to reflux and allowed to stir for two days, after which the flask was allowed to cool, and the product was extracted into ethyl acetate. The organic layer was separated from the aqueous layer, dried over sodium sulfate, 
filtered, and volatiles were removed via rotary evaporation. The product was purified via column chromatography with an 8:1 hexane/ethyl acetate mobile phase on silica. Yield: $25-35 \% .{ }^{1} \mathrm{H} \mathrm{NMR}\left(\mathrm{CDCl}_{3}\right)$ : $\delta 8.13(\mathrm{~d} 4 \mathrm{H}), 7.31(\mathrm{~d} 4 \mathrm{H}), 7.16(\mathrm{~s} 2 \mathrm{H}), 6.88(\mathrm{~s} 1 \mathrm{H}), 2.75(\mathrm{~d} 4 \mathrm{H}), 2.60(\mathrm{~d} 4 \mathrm{H}), 1.96(\mathrm{~m} \mathrm{4H}) \mathrm{ppm} . \mathrm{GCMS}$ (EI+): $[\mathrm{M}+\mathrm{H}]^{+}$calculated for $\mathrm{C}_{24} \mathrm{H}_{23} \mathrm{BrN}_{2} \mathrm{O}_{4}(\mathrm{M})$, 483.02, 485.02; observed, 483.1, 485.1.

\section{Tert-butyl-4-bromobenzoate}

Ten drops of DMF and an excess of thionyl chloride $(25 \mathrm{~mL})$ were added to a Schlenk flask maintained under nitrogen atmosphere containing 4-bromobenzoic acid (1 equiv., $5.000 \mathrm{~g}$ ) and a stir bar. The flask was fitted with a condenser and stirred under reflux for 1 hour, after which the reaction was cooled and all volatiles were removed under reduced pressure. A minimum of dry THF was then added to dissolve the resulting yellow residue, and the solution was cooled to $0{ }^{\circ} \mathrm{C}$. To this cold, stirring solution, a separately prepared solution of potassium tert-butoxide (1.2 equiv., $3.349 \mathrm{~g})$ in dry THF $(50 \mathrm{~mL})$ was added dropwise. By the time all of the tert-butoxide solution had been added the reaction was complete, and the reaction was quenched by pouring the suspension into deionized $\mathrm{H}_{2} \mathrm{O}$. The product was extracted into diethyl ether, washed with a dilute aqueous solution of $\mathrm{Na}_{2} \mathrm{CO}_{3}$, and the organic layer was separated and dried over $\mathrm{Na}_{2} \mathrm{SO}_{4}$. The pure product was contained within the organic layer, which was recovered by rotary evaporation to yield a pale yellow oil. Yield: $93 \% .{ }^{1} \mathrm{H}$ NMR $\left(\mathrm{CDCl}_{3}\right): \delta 7.84(\mathrm{~d} 2 \mathrm{H}), 7.53(\mathrm{~d} 2 \mathrm{H}), 1.58$ (s 9H) ppm. GCMS (EI+) m/z: $[\mathrm{M}+\mathrm{H}]^{+}$calculated for $\mathrm{C}_{11} \mathrm{H}_{13} \mathrm{BrO}_{2}(\mathrm{M}), 256.010,258.008$; observed, 256.1, 258.1 .

\section{Tert-butyl 4-(4,4,5,5-tetramethyl-1,3,2-dioxaborolan-2-yl)benzoate}

To a Schlenk flask under $\mathrm{N}_{2}$, potassium acetate (4.0 equiv., $3.062 \mathrm{~g}$ ), bis(pinacolato)diboron (2.0 equiv., $3.961 \mathrm{~g}),\left[1,1^{\prime}\right.$-Bis(diphenylphosphino)ferrocene]dichloropalladium(II) (0.06 equiv., $0.344 \mathrm{~g}$ ), and dry dioxane ( $\sim 30 \mathrm{~mL})$ were added. Finally, tert-butyl 4-bromobenzoate (1.0 equiv., $2.000 \mathrm{~g})$ was added, and the reaction mixture was brought to reflux temperature and stirred overnight. The mixture was then cooled to room temperature and the solvent was removed by rotary evaporation. The product was extracted into ethyl acetate, washed with water, and dried over sodium sulfate. The product was purified via silica column 
chromatography with a 1:20 ethyl acetate/hexane eluent, affording an red/orange viscous oil. Yield: $~ 80 \%$. ${ }^{1} \mathrm{H}$ NMR $\left(\mathrm{CDCl}_{3}\right): \delta 7.95(\mathrm{~d} 2 \mathrm{H}), 7.83(\mathrm{~d} 2 \mathrm{H}), 1.59$ (s $\left.9 \mathrm{H}\right), 1.35$ (s 12H) ppm. 11B-NMR(CDCl $): \delta 30.83$ (s 1B) ppm. LCMS (EI+) m/z: [M+Na] calculated for $\mathrm{C}_{17} \mathrm{H}_{25} \mathrm{BO}_{4}(\mathrm{M}), 327.1744$; observed, 327.1 .

\section{Tert-butyl 3',5'-bis(3-(4-nitrophenyl)propyl)-[1,1'-biphenyl]-4-carboxylate (t-BuBisNO$)$}

A dioxane solution $(60 \mathrm{~mL})$ containing 1-bromo-3,5-bis(p-nitrophenyl-n-propyl)benzene (1.0 equiv., 0.728 g), tert-butyl 4-(4,4,5,5-tetramethyl-1,3,2-dioxaborolan-2-yl)benzoate (1.1 equiv., $0.508 \mathrm{~g})$, and tetrakis(triphenylphosphine)palladium(0) (0.03 equiv., $0.052 \mathrm{~g}$ ) was prepared under nitrogen atmosphere. A degassed, aqueous solution of sodium hydroxide (2.0 equiv., $0.120 \mathrm{~g}$ in $10 \mathrm{~mL}$ of $\mathrm{H}_{2} \mathrm{O}$ ) was added to the dioxane solution, and the reaction mixture was stirred under reflux for 36 hours, at which point the reaction was cooled to room temperature. The product was extracted into ethyl acetate, separated from aqueous components, and dried over sodium sulfate. Finally, volatiles were removed under by rotary evaporation. The product was purified via gradient elution column chromatography first by using an eluent composed of 16:1 hexane/ethyl acetate to remove side products and starting materials. Eluent polarity was then increased by switching to a 1:1 hexane/ethyl acetate mobile phase to elute the desired product, isolated as a viscous deep red oil. Yield: 70\%. ${ }^{1} \mathrm{H}$ NMR $\left(\mathrm{CDCl}_{3}\right): \delta 8.15(\mathrm{~d} 4 \mathrm{H}), 8.04(\mathrm{~d} 2 \mathrm{H}), 7.60(\mathrm{~d} 2 \mathrm{H}), 7.33(\mathrm{~d}$ 4H), $7.25(\mathrm{~s} 2 \mathrm{H}), 6.99(\mathrm{~s} 1 \mathrm{H}), 2.79(\mathrm{t} 4 \mathrm{H}), 2.71(\mathrm{t} 4 \mathrm{H}) 2.04(\mathrm{~m} \mathrm{4H}) 1.61(\mathrm{~s} 9 \mathrm{H}) \mathrm{ppm}$. GCMS (EI+) m/z: $\left[\mathrm{M}+\mathrm{NH}_{4}\right]^{+}$calculated for $\mathrm{C}_{35} \mathrm{H}_{36} \mathrm{~N}_{2} \mathrm{O}_{6}(\mathrm{M})$, 598.26; observed, 598.3.

\section{Tert-butyl 3',5'-bis(3-(4-aminophenyl)propyl)-[1,1'-biphenyl]-4-carboxylate (t-BuBisNH $\left.\mathrm{H}_{2}\right)$}

To a vial containing a stir bar and $\mathrm{t}-\mathrm{BuBisNO}_{2}$ (1 equiv., $0.733 \mathrm{~g}$ ) were added a 10:1 solution of acetonitrile/aqueous nickel(II) acetate tetrahydrate (0.4 equiv., $0.130 \mathrm{~g})$. Sodium borohydride (8 equiv., $0.388 \mathrm{~g}$ ) was added over fifteen minutes to the stirring solution, which turned black and bubbled vigorously. Once all of the sodium borohydride had been added, the reaction was allowed to stir for 20 minutes before the product was extracted into ethyl acetate and separated from the aqueous layer by washing with saturated aqueous $\mathrm{NH}_{4} \mathrm{Cl}$. The product was purified via silica column chromatography with an eluent composed of 1:2 hexane/ethyl acetate, affording a yellow viscous oil. Yield: $\sim 70 \% .{ }^{1} \mathrm{H}$ NMR $\left(\mathrm{CDCl}_{3}\right): \delta 8.03(\mathrm{~d} 2 \mathrm{H})$, 
$7.62(\mathrm{~d} 2 \mathrm{H}), 7.24(\mathrm{~s} 2 \mathrm{H}), 7.02(\mathrm{~s} 1 \mathrm{H}), 6.99(\mathrm{~d} 4 \mathrm{H}), 6.63(\mathrm{~d} \mathrm{4H}), 3.56(\mathrm{~s} \mathrm{4H}), 2.67(\mathrm{t} 4 \mathrm{H}), 2.58(\mathrm{t} 4 \mathrm{H}) 1.94$

(m 4H) 1.61 (s 9H) ppm. GCMS (EI+) m/z: $[\mathrm{M}+\mathrm{H}]^{+}$calculated for $\mathrm{C}_{35} \mathrm{H}_{40} \mathrm{~N}_{2} \mathrm{O}_{2}(\mathrm{M}), 521.31$; observed, 521.2.

Tert-butyl-3',5'-bis(3-(4-(bis((diphenylphosphaneyl)methyl)amino)phenyl)propyl)-[1,1'-biphenyl]-4carboxylate ( $t$-BuBisPNP)

A Schlenk flask containing a magnetic stir bar and paraformaldehyde (4 equiv., $0.089 \mathrm{~g}$ ) was charged with diphenyl phosphine (4 equiv, $0.535 \mathrm{~g}$ ) under nitrogen atmosphere. A solution of t-BuBisNH $\mathrm{H}_{2}(1$ equiv., $0.373 \mathrm{~g})$ in degassed methanol $(\sim 10 \mathrm{~mL})$ was added to the flask, and the mixture was heated to reflux and stirred overnight. The reaction was then cooled to room temperature and solvent was removed under reduced pressure. The resulting residue was washed with dry pentane and the pentane solution was discarded, yielding the pure, air-sensitive product as a pale-yellow, sticky oil. Yield: $\sim 80 \%$. ${ }^{1} \mathrm{H}$ NMR $\left(\mathrm{CDCl}_{3}\right): \delta 8.04(\mathrm{~d} 2 \mathrm{H}), 7.65(\mathrm{~d} 2 \mathrm{H}), 7.43-7.24(\mathrm{~m} \mathrm{42H}), 7.07$ (s 1H), $7.01(\mathrm{~d} 4 \mathrm{H}), 6.74(\mathrm{~d} 4 \mathrm{H}), 3.96(\mathrm{~s} 8 \mathrm{H})$, $2.70(\mathrm{t} 4 \mathrm{H}), 2.59(\mathrm{t} 4 \mathrm{H}) 1.96(\mathrm{~m} 4 \mathrm{H}) 1.61(\mathrm{~s} 9 \mathrm{H}) \mathrm{ppm} .{ }^{31} \mathrm{P}$ NMR: $\delta-27.47 \mathrm{ppm}$. GCMS (EI+) $\mathrm{m} / z:[\mathrm{M}+\mathrm{Na}]^{+}$ calculated for $\mathrm{C}_{87} \mathrm{H}_{84} \mathrm{~N}_{2} \mathrm{O}_{2} \mathrm{P}_{4}(\mathrm{M})$, 1335.54; observed, 1335.537 .

\section{Deprotection of $t$-Bu ester to form BisPNP}

A solution of t-BuBisPNP (0.895 g) in DCM (6 mL) was prepared, to which trifluoroacetic acid (TFA) (2 $\mathrm{mL}$ ) was added to generate a solution containing 25\% v/v TFA. Upon stirring for two hours at room temperature the solvent was removed under reduced pressure to yield a mixture of starting materials with the desired phosphine carboxylic acid ligand as a TFA salt. Starting material was removed by washing the product with diethyl ether and removing the ether-soluble portion, affording pure product as a pale yellow sticky oil. Yield: $\sim 80 \% .{ }^{1} \mathrm{H}$ NMR $\left(\mathrm{CDCl}_{3}\right): \delta 8.16(\mathrm{~d} 2 \mathrm{H}), 7.70(\mathrm{~d} 2 \mathrm{H}), 7.50-7.21(\mathrm{~m} \mathrm{42H}), 7.09(\mathrm{~s} 1 \mathrm{H})$, $7.01(\mathrm{~d} 4 \mathrm{H}), 6.77(\mathrm{~d} 4 \mathrm{H}), 3.99(\mathrm{~s} 8 \mathrm{H}), 2.71(\mathrm{t} 4 \mathrm{H}), 2.60(\mathrm{t} 4 \mathrm{H}) 1.97(\mathrm{~m} \mathrm{4H}) \mathrm{ppm} .{ }^{31} \mathrm{P}$ NMR: -27.38 ppm. GCMS (EI+) $m / z:\left[\mathrm{M}-\mathrm{PPh}_{2}\right]^{+}$calculated for $\mathrm{C}_{83} \mathrm{H}_{76} \mathrm{~N}_{2} \mathrm{O}_{2} \mathrm{P}_{4}(\mathrm{M}), 1071.43$; observed, 1071.56.

\section{Metalation of BisPNP to form BisPNP-Ni}


Metalation was achieved using $\mathrm{Ni}[\mathrm{MeCN}]_{6} \cdot 2 \mathrm{ClO}_{4}$ that was prepared by stirring nickel(II) hydrate perchlorate in a $\mathrm{MeCN}$ solution over $\mathrm{NaSO}_{4}$ for 4 hours. To neat BisPNP ligand (1 equiv., $0.125 \mathrm{~g}, 0.10$ mmol) was added a pale blue solution of $\left[\mathrm{Ni}(\mathrm{MeCN})_{6}\right]\left(\mathrm{ClO}_{4}\right)_{2}(0.9$ equiv., $1.8 \mathrm{~mL}$ of $50 \mathrm{mM}$ solution, 0.09 mmol), which instantly turned dark red-brown upon mixing. Dry acetonitrile was added until the total volume was approximately $10 \mathrm{~mL}$. This solution was allowed to stir for two hours, at which point solvent was removed under vacuum. The resulting residue was washed with THF, and the THF-soluble portion was added to another vial and solvent was once again removed under vacuum. The residue was then washed with acetonitrile and the acetonitrile-soluble portion was discarded affording pure product as a red oil. ${ }^{1} \mathrm{H}$ NMR $\left(\mathrm{CDCl}_{3}\right): \delta 8.16(\mathrm{~d} 2 \mathrm{H}), 7.70(\mathrm{~d} 2 \mathrm{H}), 7.50-7.21(\mathrm{~m} \mathrm{42H}), 7.09(\mathrm{~s} 1 \mathrm{H}), 7.01(\mathrm{~d} 4 \mathrm{H}), 6.77(\mathrm{~d} 4 \mathrm{H}), 3.99$ (s 8H), $2.71(\mathrm{t} 4 \mathrm{H}), 2.60(\mathrm{t} 4 \mathrm{H}) 1.97(\mathrm{~m} 4 \mathrm{H}) \mathrm{ppm} .{ }^{31} \mathrm{P}-\mathrm{NMR}: 25.84 \mathrm{ppm}$.

N,N-Bis(trimethylsilyl)-4-bromoaniline $\left(\operatorname{BrPhEtN}(T M S)_{2}\right)$

A Schlenk flask was prepared with 4-bromophenylethylamine (1 equiv., $1.000 \mathrm{~g}$ ), triethylamine (2.2 equiv., $1.55 \mathrm{~mL})$, and dry DCM $(\sim 15 \mathrm{~mL})$ under nitrogen. Catalytic titanium tetrachloride $(\sim 0.10 \mathrm{~mL})$ was added dropwise via syringe through a septum until the stirring solution became deep translucent red in color. This mixture was stirred at room temperature for 1 hour, at which point chlorotrimethylsilane (2.2 equiv., 1.45 $\mathrm{mL}$ ) was added dropwise. The mixture was brought to reflux for 4 hours followed by cooling the reaction mixture to room temperature and removal of the solvent under reduced pressure. The product was extracted into diethyl ether, filtered, washed with saturated aqueous $\mathrm{NaHCO}_{3}$, and the organic layer was isolated and dried over $\mathrm{Na}_{2} \mathrm{SO}_{4}$. After vacuum filtration the solvent was removed to afford an oily mixture of desired product with starting material. The desired product was isolated from the starting material by dissolving the oil in a minimum of dry acetonitrile, which was then brought to $-20{ }^{\circ} \mathrm{C}$. The soluble portion was removed to yield pure product as large colorless crystals. Yield: $\sim 40 \%{ }^{1} \mathrm{H}-\mathrm{NMR}\left(\mathrm{CDCl}_{3}\right): \delta 7.39(\mathrm{~d} 2 \mathrm{H}), 7.01(\mathrm{~d} 2 \mathrm{H})$, 2.92 (t 2H), 2.57 (t 2H), 0.14 (s 18H) ppm. GCMS (EI+) m/z: [M+H] $]^{+}$calculated for $\mathrm{C}_{14} \mathrm{H}_{26} \mathrm{BrNSi}_{2}(\mathrm{M})$, 343.079, 345.077; observed, [M+H-CH$]^{+} 328.2,330.2$. 


\section{Wafer Preparation}

Preparation of chloride-terminated p-Si(111) wafer. This procedure follows literature precedent ${ }^{1}$. Single side polished p-type Si was used for all experiments. Si wafers were purchased from University Wafer, Inc. (B-doped Czochralski (CZ) grown p-type Si wafer (380 $\pm \mu$ m thickness), 1-5 $\Omega \cdot \mathrm{cm}$ resistivity).

Preparation of $\mathrm{Si} \mid \mathrm{PhEtN}(\mathrm{TMS})_{2} / \mathrm{CH}_{3}$ Samples. A solution of $\mathrm{BrPhEtN}(\mathrm{TMS})_{2}(0.36 \mathrm{mmol}, 0.124 \mathrm{~g})$ in approximately $20 \mathrm{~mL}$ THF was prepared in a Schlenk tube under $\mathrm{N}_{2}$ with a stir bar. The Schlenk tube was submerged in a dry ice/acetone bath and $0.32 \mathrm{mmol}$ of a $1.6 \mathrm{M} \mathrm{n}$-BuLi solution in hexanes was added to the vigorously stirring solution. This solution was allowed to stir for 30 minutes before the chlorideterminated $\mathrm{Si}(111)$ wafer was quickly transferred into the Schlenk tube and submerged in the lithiated linker solution. The solution was allowed to warm to room temperature, and after 3 hours the wafer was removed from solution, rinsed with THF, then incubated in a $1.5 \mathrm{M} \mathrm{CH}_{3} \mathrm{MgCl}$ solution at $50{ }^{\circ} \mathrm{C}$ overnight. The wafer was then rinsed copiously with THF and sonicated 5 minutes each in acetone, ethanol, and $18 \mathrm{M} \Omega \cdot \mathrm{cm}$ water. All coupling procedures were performed under $\mathrm{N}_{2}$ atmosphere.

Preparation of $\mathrm{Si} \mid \mathrm{PhEtNH}_{2} / \mathbf{C H}_{3}$ Samples. Silyl groups were removed from the surface-bound $\mathrm{PhEtN}(\mathrm{TMS})_{2}$ by incubating $\mathrm{Si} \mid \mathrm{PhEtN}(\mathrm{TMS})_{2} / \mathrm{CH}_{3}$ wafers in a $20 \% v / v$ aqueous $\mathrm{HCl}$ solution for 1 hour at room temperature. The samples were then sonicated in $18 \mathrm{M} \Omega \cdot \mathrm{cm}$ water for 5 minutes.

Activation of BisPNP-Ni and Preparation of Si|BisPNP-Ni Samples. A solution of BisPNP-Ni (1 equiv., $0.03 \mathrm{mmol}$ ), triethylamine (3 equiv., $0.009 \mathrm{~g}, 0.09 \mathrm{mmol}$ ), diisopropylcarbodiimide (1.1 equiv., $1.29 \mathrm{~mL}$ of 25.5 mmolar solution, $0.033 \mathrm{mmol}$ ), and dimethylaminopyridine (1.1 equiv., $0.004 \mathrm{~g}, 0.033 \mathrm{mmol}$ ) in dry dichloromethane was prepared under inert atmosphere and stirred for 1 hour. After this time the stirring was ceased and the $\mathbf{S i} \mid \mathbf{P h E t N H} \mathbf{H}_{2} / \mathbf{C H}_{3}$ wafer was added to the solution. After 24 hours the wafer was removed from the activated complex solution, rinsed, and sonicated for 5 minutes in dry DCM while maintained under a nitrogen atmosphere. 


\section{Photoelectrode Characterization}

X-ray Photoelectron Spectroscopy (XPS). XP spectra were obtained using a Kratos Axis Ultra X-ray photoelectron spectrometer with a monochromated $\mathrm{Al} \mathrm{K \alpha} \mathrm{X}$-ray source $(h v=1486.5 \mathrm{eV})$. Photoelectron take-off angle was $45^{\circ}$ with respect to the incident X-ray source, and analysis chamber pressure was maintained around $2 \cdot 10^{-9}$ Torr during measurements. Spectra were analyzed by the Casa XPS software (version 2.3.20rev1.2G, Casa Software Ltd.). The binding energy of each spectrum was calibrated by the Si $2 p$ peak $(99.15 \mathrm{eV})$.

Surface coverages were calculated using reported procedures ${ }^{2-4}$. Briefly, high resolution XP-spectra were recorded for elements characteristic to each surface species, namely nitrogen and nickel. Integrated intensities of these XP signals were compared to the surface coverages of atop silicon calculated from the integrated intensity of the corresponding Si $2 p$ high resolution XP-spectrum. Surface coverage values were scaled to account for the number of characteristic atoms per surface moiety, for example there are three nitrogen atoms in one Si|BisPNP unit, so the atomic concentrations were divided by three to give the reported surface concentration per $\operatorname{Si}(111)$ atop site.

Nuclear Magnetic Resonance (NMR). ${ }^{1} \mathrm{H}$ and ${ }^{31} \mathrm{P}-\mathrm{NMR}$ spectra were generated using a Varian $400 \mathrm{MHz}$ NMR system with Oxford NMR AS400 Magnet (Varian, Inc., Palo Alto, CA). ${ }^{11}$ B-NMR spectra were generated using a Bruker AVANCE III 500 MHz NMR (Billerica, MA).

Mass Spectrometry (MS). Liquid chromatography/mass spectrometry (LCMS) spectra were generated using an Agilent 6130 Series Quadrupole LC/MS System, and gas chromatography/mass spectrometry (GCMS) spectra were generated using an Agilent 5977E Series GC/MSD System (Agilent Technologies, Santa Clara, CA).

Electrochemical Measurements. All measurements were performed using a Gamry Interface 1000 Potentiostat/Galvanostat/ZRA (Gamry Instruments Inc., Warminster, PA). A three-electrode electrochemical cell was constructed consisting of a Pt mesh counter electrode (99.95\%, Strem Chemicals, 
USA), a Ag wire quasi-reference electrode (CH Instruments, Inc., USA), and a Si wafer working electrode immobilized (p-type: University Wafer, Silicon Prime wafers, doping: boron, thickness: $380 \pm 25 \mu \mathrm{m}$, orientation: (111), resistivity: 1-5 $\Omega \cdot \mathrm{cm}$; $\mathbf{n}^{+}$-type: Virginia Semiconductor, doping: arsenic, thickness: 500 $\pm 25 \mu \mathrm{m}$, orientation: (111), resistivity: $\leq 0.004 \Omega \cdot \mathrm{cm}$ ) in a Teflon and stainless steel housing. The Si wafer was electrically connected to $\mathrm{Cu}$ tape (Electron Microscopy Sciences, USA) by GaIn eutectic (99.99\%, Alfa Aesar) and secured under an o-ring, providing an electrode active area of $0.07 \mathrm{~cm}^{2}$. Illumination was provided by a broadband LED lamp (Osram Sylvania Inc., Ultra LED $50 \mathrm{~W}$ ), and the light intensity was measured as $\sim 33 \mathrm{~mW} \mathrm{~cm} \mathrm{~cm}^{-2}$. All electrochemical measurements were made under $\mathrm{N}_{2}$ atmosphere with electrodes in contact with a $\mathrm{MeCN}$ solution of $0.2 \mathrm{M} \mathrm{LiClO}_{4}$ supporting electrolyte. The $\mathrm{Fc} / \mathrm{Fc}^{+}$redox couple was used as an internal reference at the end of each experiment $\left(0 \mathrm{~V}\right.$ vs $\mathrm{Fc} / \mathrm{Fc}^{+}=0.251 \mathrm{~V}$ vs $\left.\mathrm{Ag}\right)$.

Cyclic Voltammetry (CV). Cyclic voltammetry experiments were performed in quiescent solutions under illumination with a scan rate of $25 \mathrm{mV} / \mathrm{s}$. $V_{o n}$ was defined by the intersection of two linear fits generated from the flat region in the J-V curves before current onset and the interval of stable slope in the region of increasing current density. Average $\mathrm{V}_{\text {on }}$ values were calculated from eight samples of each modified photoelectrode that were cut from four different surface preparation procedures. The preparation of $[\mathrm{H}(\mathrm{dmf})] \mathrm{OTf}$, used in acid titration cyclic voltammetry experiments, is discussed elsewhere ${ }^{5}$.

Electrochemical Impedance Spectroscopy (EIS). A sinusoidal $10 \mathrm{mV}_{\mathrm{RMS}}$ AC signal was scanned between $1 \mathrm{~Hz}$ and $1 \mathrm{MHz}$ with DC offset potentials spanning the onset of HER. For p-type samples this was performed under illuminated conditions. All electrodes were in contact with $6 \mathrm{mM}[\mathrm{H}(\mathrm{dmf})] \mathrm{OTf}$. Equivalent circuit (EC) models were generated to account for prominent electron polarization phenomena involved in charge transfer at the electrode $\mid$ solution interface, and equivalent circuit element parameters were extracted by fitting these EC models to the acquired EIS data using the Gamry Echem Analyst software. $\mathrm{C}_{\text {eff }}$ values were calculated via the following equation ${ }^{6}$

$$
\mathrm{C}_{\mathrm{dl}}=\mathrm{Y}_{\mathrm{CPE}}\left(\omega_{\max }^{\prime \prime}\right)^{\propto-1}
$$


Where $\mathrm{Y}_{\mathrm{CPE}}$ is the extracted CPE admittance, $\omega_{\max }^{\prime \prime}$ represents the frequency at which the imaginary part of the impedance (Z') has a maximum, and $\alpha$ is the CPE exponent.

Mott-Schottky Analysis. EIS spectra were taken in the dark, scanning from $1 \mathrm{~Hz}$ to $1 \mathrm{MHz}$ with DC offset potentials stepped at $50 \mathrm{mV}$ increments typically between potentials of -0.55 and $-1.50 \mathrm{~V}$ vs $\mathrm{Fc} / \mathrm{Fc}^{+}$. These EIS data were fit to Simplified Randles cells at each potential in the frequency regime in which the parallel capacitance dominated the impedance, generally between $10^{3}$ and $10^{5} \mathrm{~Hz}$. Effective capacitance values were extracted, and the reciprocal capacitance values squared were plotted versus the applied DC potential. Flat band potentials were calculated by extrapolating a line of best fit generated from the linear region of the Mott Schottky plot to the x-intercept, followed by subtraction of the thermal voltage, $k_{\mathrm{B}}$ T/e. All Mott Schottky analysis was performed using a custom LabVIEW program supplied by Ron Grimm ${ }^{7}$. The contacting solution-phase redox couple in these experiments was $6 \mathrm{mM}[\mathrm{H}(\mathrm{dmf})] \mathrm{OTf}$. 

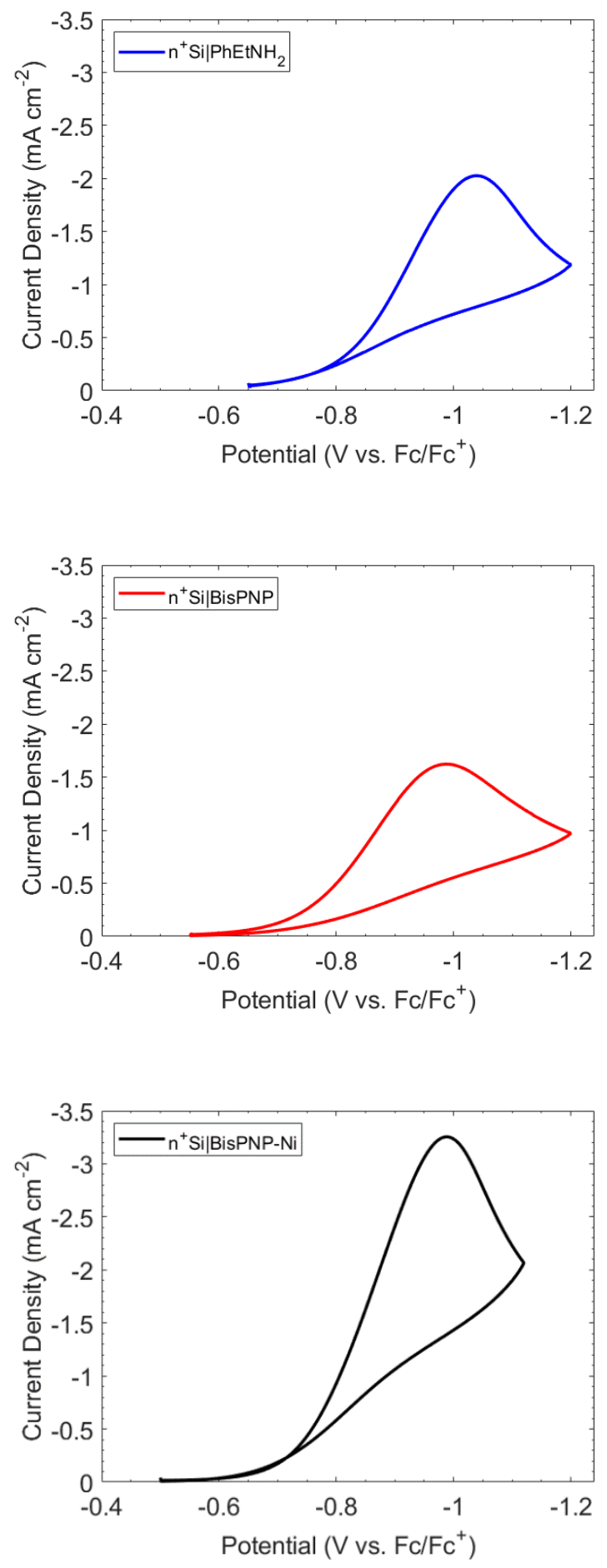

Figure S1: Representative cyclic voltammetry traces of modified $\mathrm{n}^{+}$-doped $\mathrm{Si}(111)$ electrodes. CV scans were taken in the dark, in contact with $0.2 \mathrm{M} \mathrm{LiClO} 4$ and $6 \mathrm{mM}[\mathrm{H}(\mathrm{dmf})] \mathrm{OTf}$ in MeCN. Data from $\mathbf{n}^{+}-$ Si|Me samples were not included due to sample instability. 
Nyquist
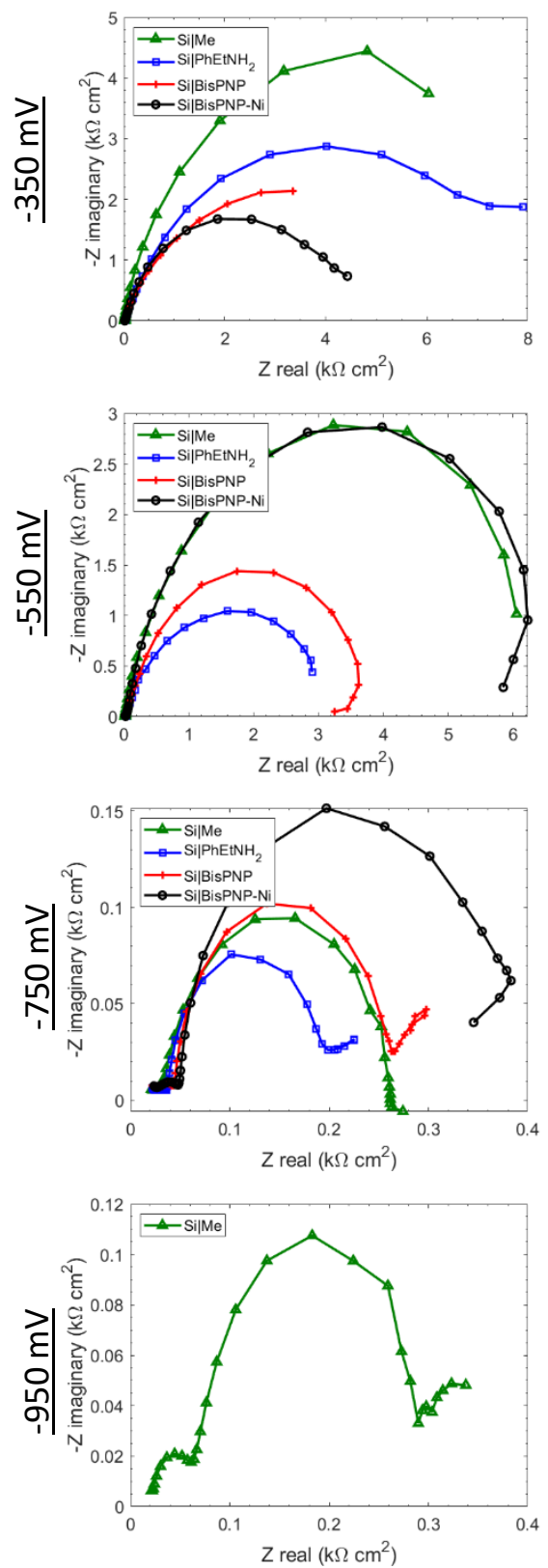

Bode Modulus
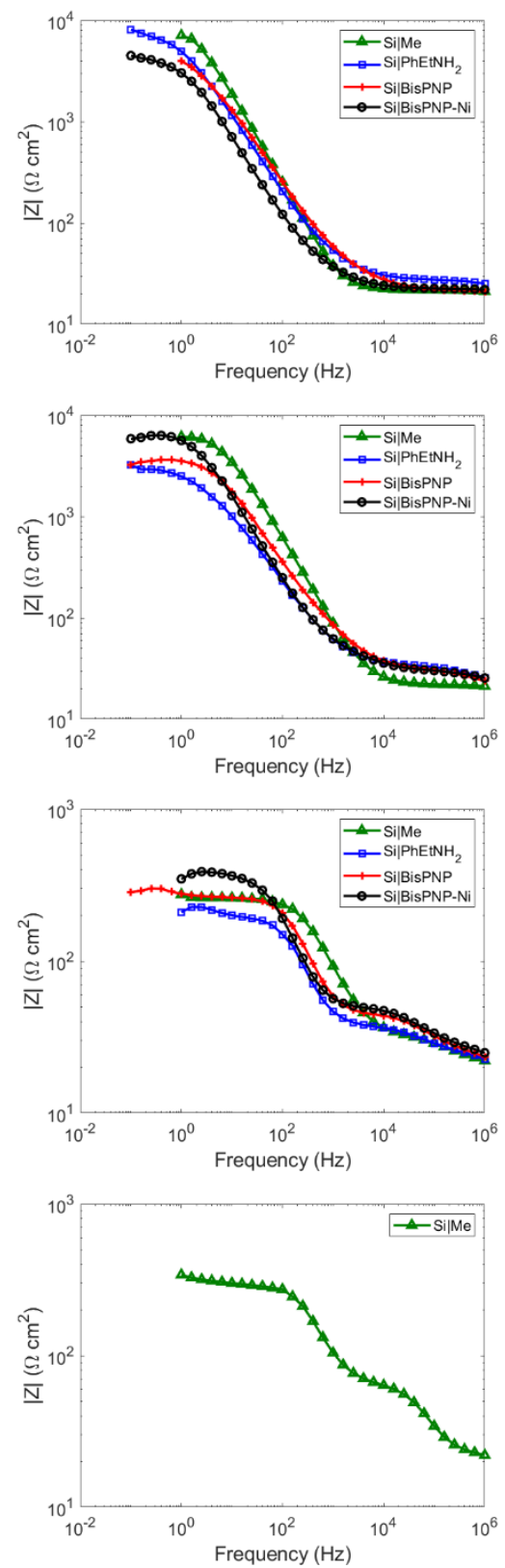

Bode Phase
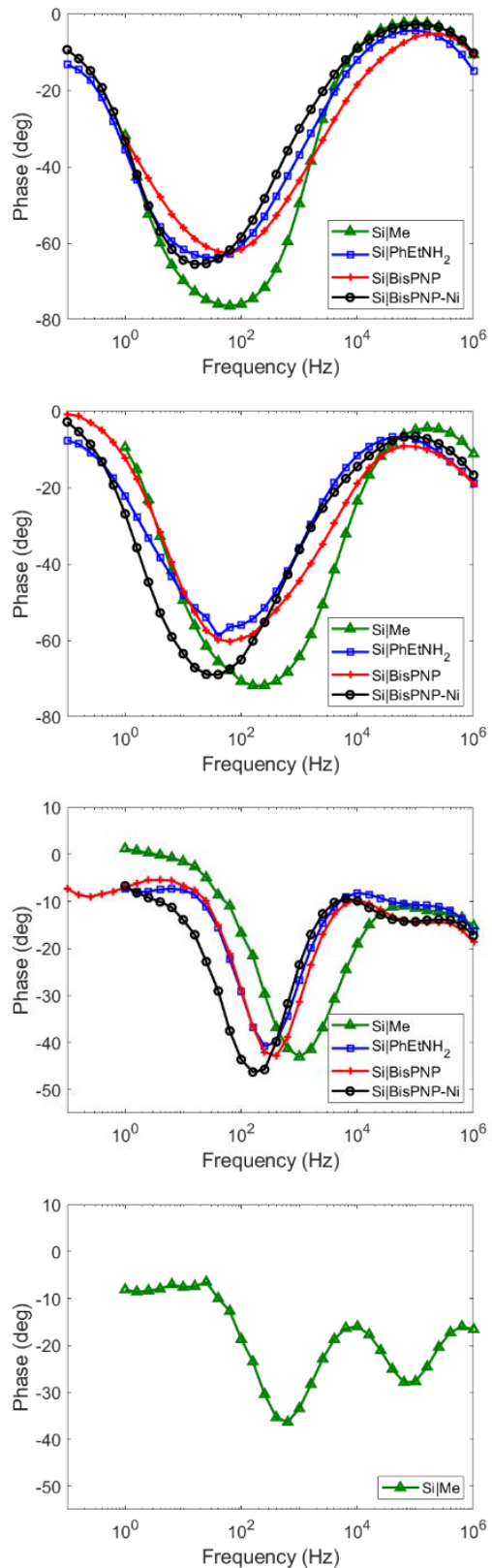

Figure S2: Representative EIS data of modified p-Si(111) photoelectrodes taken under illumination in the presence of $6 \mathrm{mM}[\mathrm{H}(\mathrm{dmf})] \mathrm{OTf}$ and $0.2 \mathrm{M} \mathrm{LiClO}_{4}$. The columns tabulate Nyquist, Bode modulus, and Bode phase plots from left to right, and the rows tabulate EIS data measured with DC offset potentials of $-350,-550,-750$, and $-950 \mathrm{mV}$ vs Fc from top to bottom. The lines connecting data points in these plots are meant to guide the eye and are not EC fits of the data. 
Nyquist
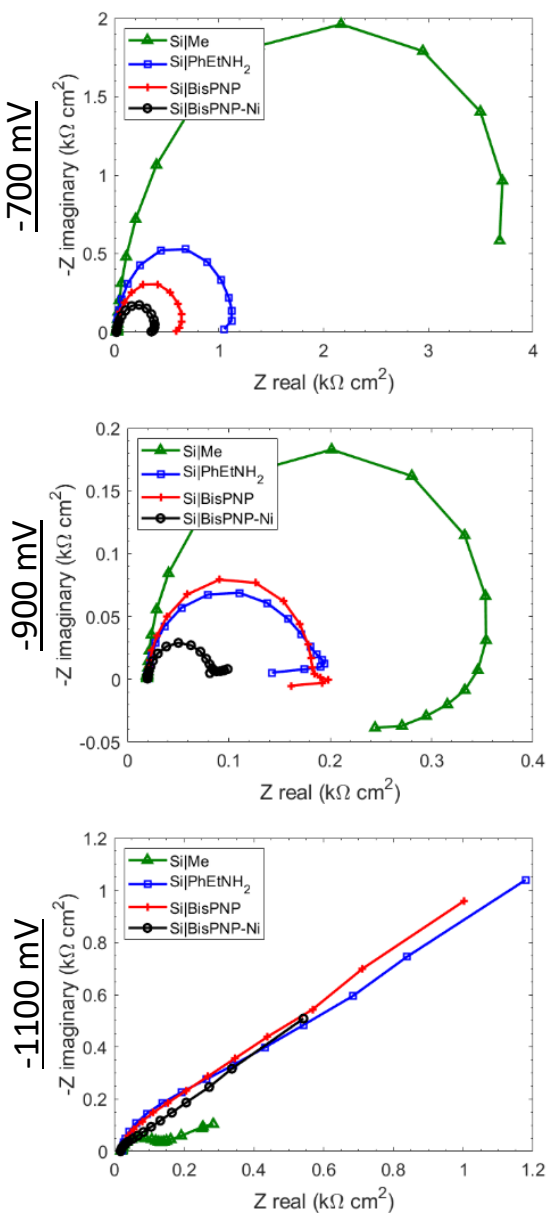

Bode Modulus
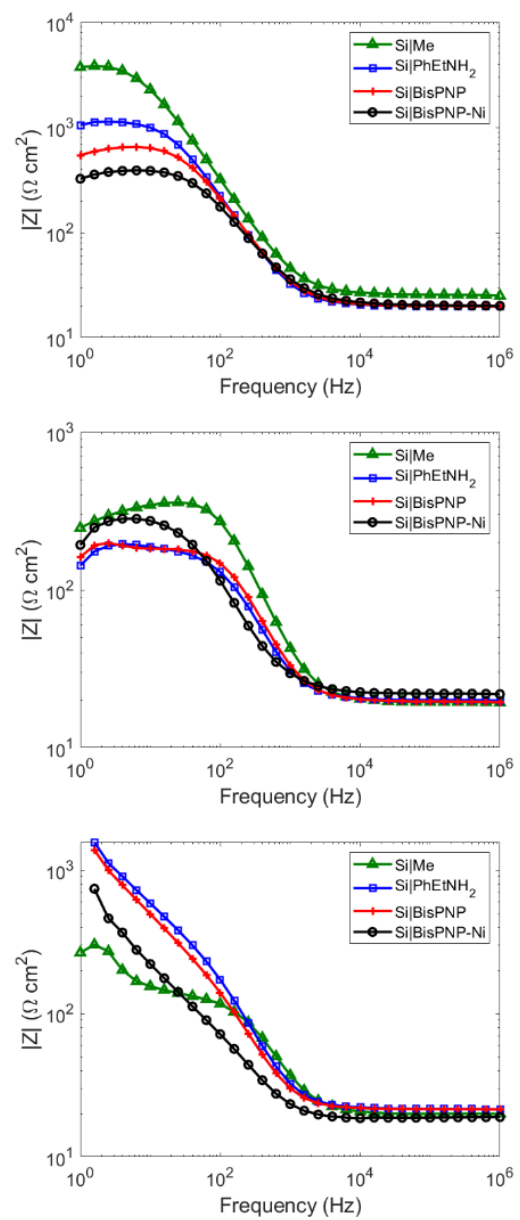

Bode Phase
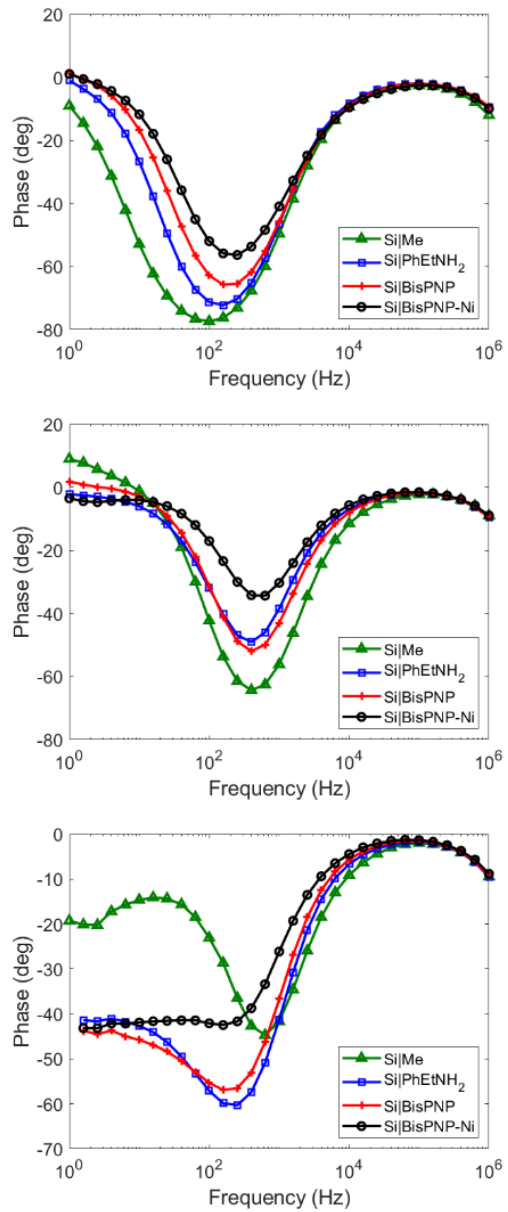

Figure S3: Representative EIS data of modified $\mathrm{n}^{+}-\mathrm{Si}(111)$ photoelectrodes taken in the dark in the presence of 6 $\mathrm{mM}[\mathrm{H}(\mathrm{dmf})] \mathrm{OTf}$ and $0.2 \mathrm{M} \mathrm{LiClO}_{4}$. The columns tabulate Nyquist, Bode modulus, and Bode phase plots from left to right, and the rows tabulate EIS data measured with DC offset potentials of -900 and $-1100 \mathrm{mV}$ vs Fc from top to bottom. The lines connecting data points in these plots are meant to guide the eye and are not EC fits of the data. 


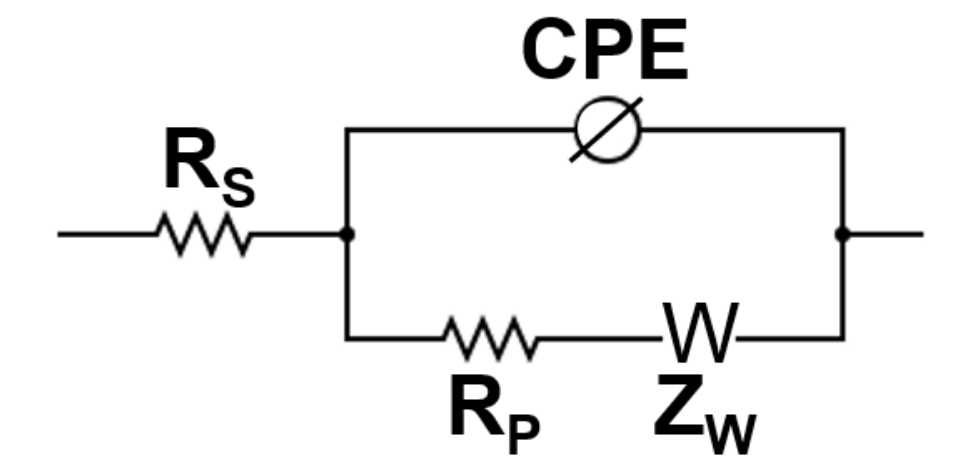

Figure S4: Equivalent circuit diagram for $\mathrm{n}^{+}$modified silicon electrodes at DC offset potentials negative of the onset for HER. This EC model consists of series resistance $\left(R_{S}\right)$, polarization resistance $\left(R_{P}\right)$, a Warburg impedance element $\left(\mathrm{Z}_{\mathrm{W}}\right)$, and a constant phase element (CPE). EIS was performed on $\mathrm{n}^{+}$samples in the dark. 

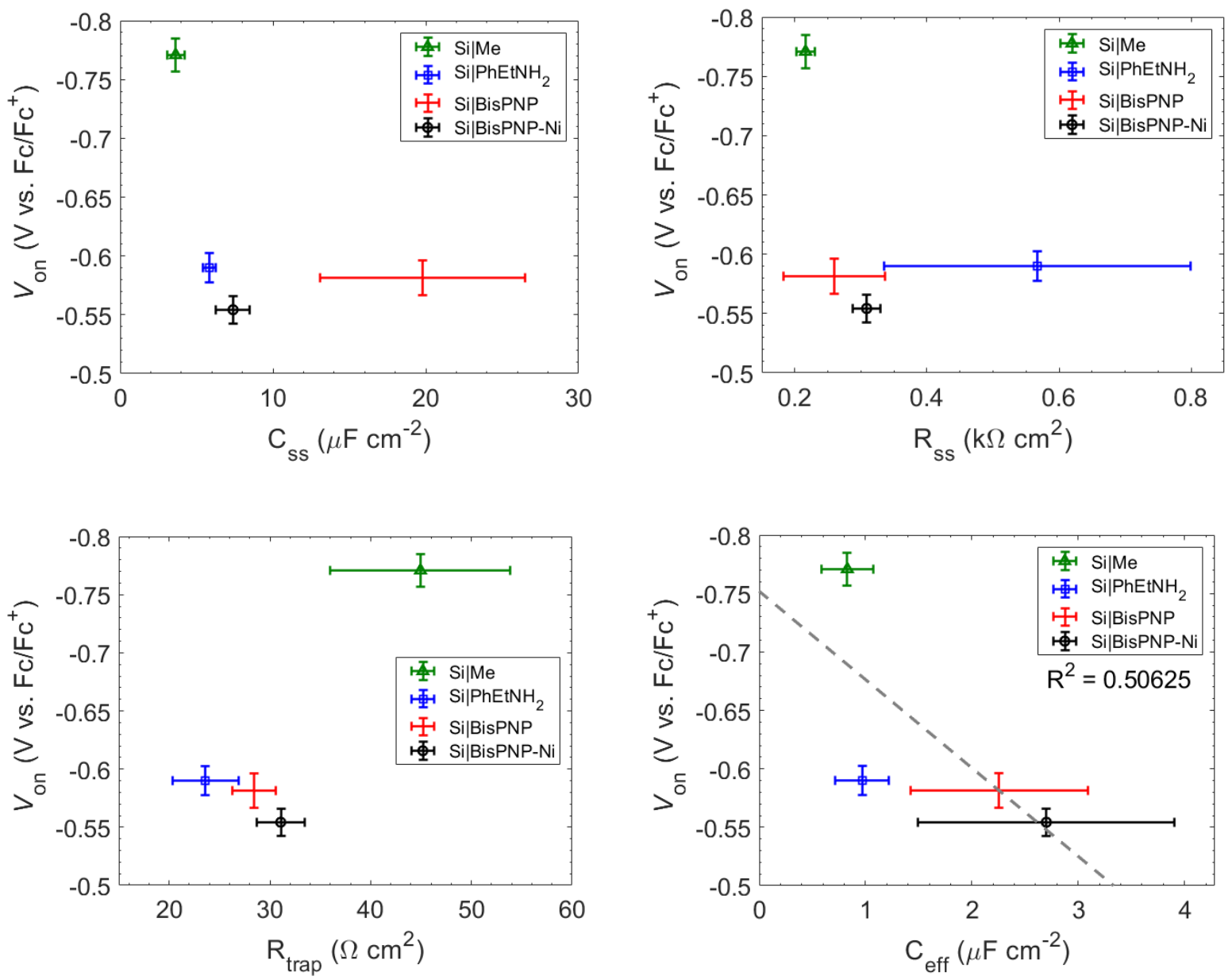

Figure S5: Plots of $V_{\text {on }}$ versus average equivalent circuit element parameters corresponding to hydrogen evolution electron polarization events $\left(\mathrm{C}_{\mathrm{ss}}, \mathrm{R}_{\mathrm{ss}}, \& \mathrm{R}_{\text {trap }}\right)$ and silicon depletion layer effective capacitance $\left(\mathrm{C}_{\text {eff }}\right)$. EC parameters were extracted from fitting EIS data to the combination of Randles circuits presented in the main text, Figure 6B. This data displays the lack of clear correlation between the $V_{\text {on }}$ for HER with EC element parameters associated with HER and an apparent weak trend between $V_{\text {on }}$ and $\mathrm{C}_{\text {eff. }}$. 
Table S1. Compilation of all EC parameters extracted from fitting the combination of Randles circuits shown in Figure 6B to EIS data of modified p-Si(111) photoelectrodes generated under illumination with DC applied potentials negative of HER $V_{\text {on. }}$. Photoelectrodes were in contact with $6 \mathrm{mM}[\mathrm{H}(\mathrm{dmf})] \mathrm{OTf}$ in MeCN containing $0.2 \mathrm{mM} \mathrm{LiClO}_{4}$.

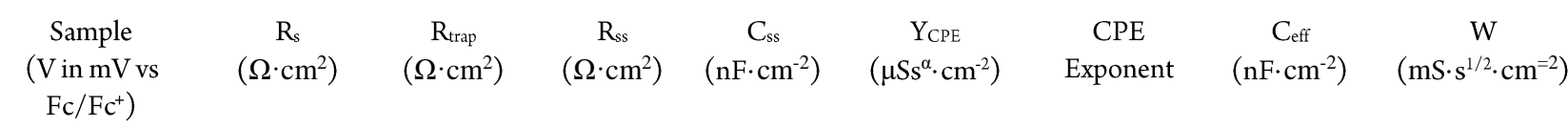

\begin{tabular}{|c|c|c|c|c|c|c|c|c|}
\hline $\begin{array}{c}\mathrm{p}-\mathrm{Si} \mid \mathrm{Me} \\
(-950)\end{array}$ & $19 \pm 3$ & $45 \pm 22$ & $216 \pm 34$ & $4 \pm 1$ & $10 \pm 7$ & $0.66 \pm 0.05$ & $829 \pm 605$ & $4 \pm 2$ \\
\hline $\begin{array}{c}\mathrm{p}-\mathrm{Si} \mid \mathrm{PhEtNH}_{2} \\
(-750)\end{array}$ & $17 \pm 7$ & $24 \pm 8$ & $\begin{array}{c}567 \pm \\
569\end{array}$ & $6 \pm 1$ & $9 \pm 9$ & $0.64 \pm 0.08$ & $970 \pm 620$ & $47 \pm 66$ \\
\hline $\begin{array}{c}\mathrm{p}-\mathrm{Si} \mid \mathrm{BisPNP} \\
(-750)\end{array}$ & $17 \pm 6$ & $28 \pm 7$ & $\begin{array}{c}259 \pm \\
244\end{array}$ & $20 \pm 21$ & $19 \pm 20$ & $0.64 \pm 0.14$ & $\begin{array}{c}2257 \pm \\
2500\end{array}$ & $9 \pm 10$ \\
\hline $\begin{array}{c}\mathrm{p}-\mathrm{Si} \mid \mathrm{BisPNP}-\mathrm{Ni} \\
(-750)\end{array}$ & $19 \pm 4$ & $29 \pm 5$ & $308 \pm 67$ & $7 \pm 3$ & $21 \pm 30$ & $0.60 \pm 0.16$ & $\begin{array}{c}2500 \pm \\
3267\end{array}$ & $8 \pm 5$ \\
\hline
\end{tabular}

Table S2. Compilation of all EC parameters extracted from fitting the combination of Randles circuits shown in Figure S3 to EIS data of modified $\mathbf{n + - S i ( 1 1 1 )}$ photoelectrodes generated in the dark with DC applied potentials negative of HER $V_{\text {on }}$. Photoelectrodes were in contact with $6 \mathrm{mM}[\mathrm{H}(\mathrm{dmf})] \mathrm{OTf}$ in MeCN containing $0.2 \mathrm{mM} \mathrm{LiClO}_{4}$.

\begin{tabular}{|c|c|c|c|c|c|c|}
\hline $\begin{array}{c}\text { Sample } \\
\left(\mathrm{V} \text { in } \mathrm{mV} \text { vs } \mathrm{Fc} / \mathrm{Fc}^{+}\right)\end{array}$ & $\begin{array}{c}\mathrm{R}_{\mathrm{s}} \\
\left(\Omega \cdot \mathrm{cm}^{2}\right. \\
)\end{array}$ & $\begin{array}{c}\mathrm{R}_{\mathrm{p}} \\
\left(\Omega \cdot \mathrm{cm}^{2}\right)\end{array}$ & $\begin{array}{c}Y_{\mathrm{CPE}} \\
\left(\mu S \cdot \mathrm{s}^{\alpha} \cdot \mathrm{cm}^{-2}\right)\end{array}$ & $\begin{array}{c}\text { CPE } \\
\text { Exponent }\end{array}$ & $\begin{array}{c}C_{\text {eff }} \\
\left(\mu \mathrm{F} \cdot \mathrm{cm}^{-2}\right)\end{array}$ & $\begin{array}{c}\mathrm{W} \\
\left(\mu \mathrm{S} \cdot \mathrm{s}^{1 / 2} \cdot \mathrm{cm}^{-2}\right)\end{array}$ \\
\hline $\begin{array}{c}\mathrm{n}^{+}-\mathrm{Si} \mid \mathrm{Me} \\
(-1300)\end{array}$ & $24 \pm 2$ & $117 \pm 6$ & $11 \pm 2$ & $0.96 \pm 0.01$ & $8 \pm 1$ & $957 \pm 407$ \\
\hline $\begin{array}{c}\mathrm{n}^{+}-\mathrm{Si} \mid \mathrm{PhEtNH} 2 \\
(-1100)\end{array}$ & $20 \pm 1$ & $240 \pm 35$ & $13 \pm 4$ & $0.95 \pm 0.02$ & $10 \pm 2$ & $365 \pm 121$ \\
\hline $\begin{array}{c}\mathrm{n}^{+}-\mathrm{Si} \mid \mathrm{BisPNP} \\
(-1100)\end{array}$ & $21 \pm 1$ & $180 \pm 54$ & $20 \pm 8$ & $0.94 \pm 0.03$ & $13 \pm 4$ & $618 \pm 555$ \\
\hline $\begin{array}{c}\mathrm{n}^{+}-\mathrm{Si} \mid \mathrm{Bis} P N P-N i \\
(-1100)\end{array}$ & $20 \pm 1$ & $42 \pm 16$ & $14 \pm 1$ & $0.99 \pm 0.01$ & $12 \pm 1$ & $545 \pm 99$ \\
\hline
\end{tabular}




\section{References}

(1) Seo, J.; Pekarek, R. T.; Rose, M. J. Photoelectrochemical Operation of a Surface-Bound, NickelPhosphine $\mathrm{H}_{2}$ Evolution Catalyst on p-Si(111): A Molecular Semiconductor|catalyst Construct. Chem. Commun. 2015, 51, 13264-13267.

(2) Webb, L. J.; Nemanick, E. J.; Biteen, J. S.; Knapp, D. W.; Michalak, D. J.; Traub, M. C.; Chan, A. S. Y.; Brunschwig, B. S.; Lewis, N. S. High-Resolution X-Ray Photoelectron Spectroscopic Studies of Alkylated Silicon(111) Surfaces. J. Phys. Chem. B 2005, 109, 3930-3937.

(3) Nemanick, E. J.; Hurley, P. T.; Brunschwig, B. S.; Lewis, N. S. Chemical and Electrical Passivation of Silicon (111) Surfaces through Functionalization with Sterically Hindered Alkyl Groups. J. Phys. Chem. B 2006, 110, 14800-14808.

(4) Li, F.; Basile, V. M.; Pekarek, R. T.; Rose, M. J. Steric Spacing of Molecular Linkers on Passivated Si(111) Photoelectrodes. ACS Appl. Mater. Interfaces 2014, 6, 20557-20568.

(5) Favier, I.; Duñach, E. New Protic Salts of Aprotic Polar Solvents. Tetrahedron Lett. 2004, 45, 3393-3395.

(6) Hsu, C. H.; Mansfeld, F. Concerning the Conversion of the Constant Phase Element Parameter $\mathrm{Y}_{0}$ into a Capacitance. Corrosion 2001, 57, 747.

(7) Grimm, R. L.; Bierman, M. J.; O’Leary, L. E.; Strandwitz, N. C.; Brunschwig, B. S.; Lewis, N. S. Comparison of the Photoelectrochemical Behavior of H-Terminated and Methyl-Terminated $\mathrm{Si}(111)$ Surfaces in Contact with a Series of One-Electron, Outer-Sphere Redox Couples in $\mathrm{CH}_{3}$ CN. J. Phys. Chem. C 2012, 116, 23569-23576. 